\title{
On the Metric Dimension of Some Operation Graphs
}

\author{
Marsidi1 $^{1}$ Ika Hesti Agustin², Dafik ${ }^{3}$, Ridho Alfarisi ${ }^{4}$, Hendrik Siswono ${ }^{5}$ \\ ${ }^{1}$ Mathematics Edu. Depart. IKIP PGRI Jember Indonesia \\ ${ }^{2}$ Mathematics Depart. University of Jember Indonesia \\ ${ }^{3}$ Mathematics Edu. Depart. University of Jember Indonesia \\ ${ }^{4}$ Elementary School Teacher Edu. Depart. University of Jember Indonesia \\ ${ }^{5}$ Majoring in Early Childhood Edu. Depart. IKIP PGRI Jember Indonesia
}

Email:marsidiarin@gmail.com, ikahesti@fmipa.unej.ac.id,d.dafik@gmail.com

\begin{abstract}
Let $G$ be a simple, finite, and connected graph. An ordered set of vertices of a nontrivial connected graph $G$ is $W=\left\{w_{1}, w_{2}, w_{3}, \ldots, w_{k}\right\}$ and the $k$-vector $r(v \mid W)=\left(d\left(v, w_{1}\right), d\left(v, w_{2}\right), \ldots, d\left(v, w_{k}\right)\right)$ represent vertex $v$ that respect to $W$, where $v \in G$ and $d\left(v, w_{i}\right)$ is the distance between vertex $v$ and $w_{i}$ for $1 \leq i \leq k$. The set $W$ called a resolving set for $G$ if different vertex of $G$ have different representations that respect to $W$. The minimum cardinality of resolving set of $G$ is the metric dimension of $G$, denoted by $\operatorname{dim}(G)$. In this paper, we give the local metric dimension of some operation graphs such as joint graph $P_{n}+C_{m}$, amalgamation of parachute, amalgamation of fan, and $\operatorname{shack}\left(H_{2}^{2}, e, m\right)$.
\end{abstract}

Keywords: metric dimension, resolving set, operation graphs.

\section{INTRODUCTION}

All graphs in this paper are simple, finite and connected, for basic definition of graph we can see in Chartrand [1]. Chartrand [2] define the length of a shortest path between two vertices $u$ and $v$ is the distance $d(u, v)$ between two vertices in a connected graph $G$. An ordered set of vertices of a nontrivial connected graph $G$ is $W=$ $\left\{w_{1}, w_{2}, w_{3}, \ldots, w_{k}\right\}$ and the $k$-vector $r(v \mid W)=\left(d\left(v, w_{1}\right), d\left(v, w_{2}\right), \ldots, d\left(v, w_{k}\right)\right)$ represent vertex $v$ that respect to $W$. The set $W$ called a resolving set for $G$ if different vertex of $G$ have different representations that respect to $W$. The minimum of cardinality of resolving set of $\mathrm{G}$ is the metric $\operatorname{dimension}$ of $G$, denoted by $\operatorname{dim}(G)$ [3].

There are many articles explained about metric dimension such as [2], [4], [5], [6], and [7]. [8] defined a shackle graphs $\operatorname{shack}\left(G_{1}, G_{2}, \ldots, G_{k}\right)$ constructed by nontrivial connected graphs $G_{1}, G_{2}, \ldots, G_{k}$ such that $G_{i}$ and $G_{j}$ have no a common vertex for every $i, j \in[1, k]$ with $|i-j| \geq 2$, and for every $l \in[1, k-1], G_{l}$ and $G_{l+1}$ share exactly one common vertex (called linkage vertex) and the $k-1$ linking vertices are all different. [9] defined an amalgamation of graphs constructed from isomorphic connected graphs $H$ and the choice of the vertex $v_{j}$ as a terminal is irrelevant. For any $k$ positive integer, we denote such an amalgamation by $\operatorname{amal}(H, k)$, where $k$ denotes the number of copies of $H$.

Proposition 1. [2] Let $G$ be a connected graph or order $n \geq 2$, then the following hold:

a. $\operatorname{dim}(G)=1$ if and only if graph $G$ is a path graph

b. $\operatorname{dim}(G)=n-1$ if and only if graph $G$ is a complete graph

c. For $n \geq 3, \operatorname{dim}\left(C_{n}\right)=2$ 
d. For $n \geq 4, \operatorname{dim}(G)=n-2$ if and only if $G=K_{p, q}(p, q \geq 1), G=$ $K_{p}+\overline{K_{q}}(p \geq 1, q \geq 2)$.

\section{RESULTS AND DISCUSSION}

Theorem 2.1. For $n \geq 2$ and $m \geq 7$, the metric dimension of joint graph $P_{n}+C_{m}$ is $\operatorname{dim}\left(P_{n}+C_{m}\right)=\left\lceil\frac{n}{2}\right\rceil+\left\lfloor\frac{m-1}{2}\right\rfloor$.

Proof. The joint of path and cycle graph, denoted by $P_{n}+C_{m}$ is a connected graph with vertex set $V\left(P_{n}+C_{m}\right)=\left\{x_{j} ; 1 \leq j \leq n\right\} \cup\left\{y_{l} ; 1 \leq l \leq m\right\}$ and edge set $E\left(P_{n}+C_{m}\right)=$ $\left\{x_{j} y_{l} ; 1 \leq j \leq n ; 1 \leq l \leq m\right\} \cup\left\{x_{j} x_{j+1} ; 1 \leq j \leq n-1\right\} \cup\left\{y_{l} y_{l+1} ; 1 \leq l \leq m-1\right\} \cup$

$\left\{y_{n} y_{1}\right\}$. The cardinality of vertex set and edge set, respectively are $\left|V\left(P_{n}+C_{m}\right)\right|=n+$ $m$ and $\left|E\left(P_{n}+C_{m}\right)\right|=n(m+1)+m$.

If we show that $\operatorname{dim}\left(P_{n}+C_{m}\right)=\left\lceil\frac{n}{2}\right\rceil+\left\lfloor\frac{m-1}{2}\right\rfloor$ for $n \geq 2$ dan $m \geq 7$, then we will show the lower bound namely $\operatorname{dim}\left(P_{n}+C_{m}\right) \geq\left\lceil\frac{n}{2}\right\rceil+\left\lfloor\frac{m-1}{2}\right\rfloor-1$. Assume that $\operatorname{dim}\left(P_{n}+\right.$ $\left.C_{m}\right)<\left\lceil\frac{n}{2}\right\rceil+\left\lfloor\frac{m-1}{2}\right\rfloor$. This can be shown with take resolving set $W=\left\{x_{1}, y_{1}, y_{5}\right\}$ so that it obtained the representation of the vertices $x, y \in V\left(P_{2}+C_{7}\right)$ respect to $W$.

It can be seen that there is at least two vertices in $P_{n}+C_{m}$ which have the same representation respect to $W$, one of them is $r\left(y_{4} \mid W\right)=(1,2,1)$ and $r\left(y_{6} \mid W\right)=(1,2,1)$ such that we have the cardinality of resolving set of $\operatorname{dim}\left(P_{n}+C_{m}\right) \geq\left\lceil\frac{n}{2}\right\rceil+\left\lfloor\frac{m-1}{2}\right\rfloor$.

Furthermore, we will prove that $\operatorname{dim}\left(P_{n}+C_{m}\right) \leq\left\lceil\frac{n}{2}\right\rceil+\left\lfloor\frac{m-1}{2}\right\rfloor$ with determine the resolving set $W=\left\{x_{j} ; 1 \leq j \leq 2\left\lfloor\frac{n}{2}\right\rfloor ; i \in\right.$ odd $\} \cup\left\{y_{l} ; 1 \leq l \leq 2\left\lfloor\frac{m-1}{2}\right\rfloor ; j \in\right.$ odd $\}$. So, we have the cardinality of resolving set of $P_{n}+C_{m}$ namely $|W|=\frac{2\left\lceil\frac{n}{2}\right\rceil}{2}+\frac{2\left\lceil\frac{m-1}{2}\right\rceil}{2}=\left\lfloor\frac{n}{2}\right\rfloor+\left\lfloor\frac{m-1}{2}\right\rfloor$. The representation of the vertices $y \in F_{n}$ and $x \in F_{n}$ respect to $W$ as follows.

$$
\begin{gathered}
r\left(x_{j} \mid W\right)=\left\{\left(a_{i j}\right) ; 1 \leq j \leq n, 1 \leq i \leq\left(\left\lceil\frac{n}{2}\right\rceil+1\right)+\left(\left\lfloor\frac{m-1}{2}\right\rfloor\right)\right\}, \text { where } \\
a_{i j}=\left\{\begin{array}{l}
0 ; \text { for } i=\frac{j+1}{2}, 1 \leq j \leq n, j \in \text { odd } \\
1 ; \text { for }\left(\left\lceil\frac{n}{2}\right\rceil+1\right) \leq i \leq\left(\left\lceil\frac{n}{2}\right\rceil+1\right)+\left(\left\lfloor\frac{m-1}{2}\right\rfloor\right), 1 \leq j \leq n \\
\text { or } i=\frac{j}{2}, 2 \leq j \leq n, j \in \text { even or } i=\frac{j}{2}+1,2 \leq j \leq n, j \in \text { even } \\
2 ; \text { for } i, j=\text { otherwise }
\end{array}\right. \\
r\left(y_{l} \mid W\right)=\left\{\left(a_{i j}\right) ; 1 \leq j \leq m, 1 \leq i \leq\left(\left\lceil\frac{n}{2}\right\rceil+1\right)+\left(\left\lfloor\frac{m-1}{2}\right\rfloor\right)\right\}, \text { where } \\
a_{i j}=\left\{\begin{array}{l}
0 ; \text { for } i=\left(\left\lceil\frac{n}{2}\right\rceil\right)+\frac{j+1}{2}, 1 \leq j \leq m-2, j \in \text { odd } \\
1 ; \text { for } 1 \leq i \leq\left(\left\lceil\frac{n}{2}\right\rceil\right), 1 \leq j \leq m-2 \\
\text { or } i=\left(\left\lceil\frac{n}{2}\right\rceil\right)+\frac{j}{2}, 2 \leq j \leq m, j \in \text { even } \\
\text { or } i=\left(\left\lceil\frac{n}{2}\right\rceil\right)+\frac{j+1}{2}+1,2 \leq j \leq m, j \in \text { even } \\
2 ; \text { for } i, j=\text { otherwise }
\end{array}\right.
\end{gathered}
$$

It can be seen that every vertex in $P_{n}+C_{m}$ have distinct representation respect to $W$, such that the cardinality of resolvng set in $P_{n}+C_{m}$ is $\left\lceil\frac{n}{2}\right\rceil+\left\lfloor\frac{m-1}{2}\right\rfloor$ or $\operatorname{dim}\left(F_{n}\right) \leq\left\lceil\frac{n}{2}\right\rceil+$ $\left\lfloor\frac{m-1}{2}\right\rfloor$. Thus, we conclude that $\operatorname{dim}\left(P_{n}+C_{m}\right)=\left\lceil\frac{n}{2}\right\rfloor+\left\lfloor\frac{m-1}{2}\right\rfloor$ for $n \geq 2$ and $m \geq 7$. 


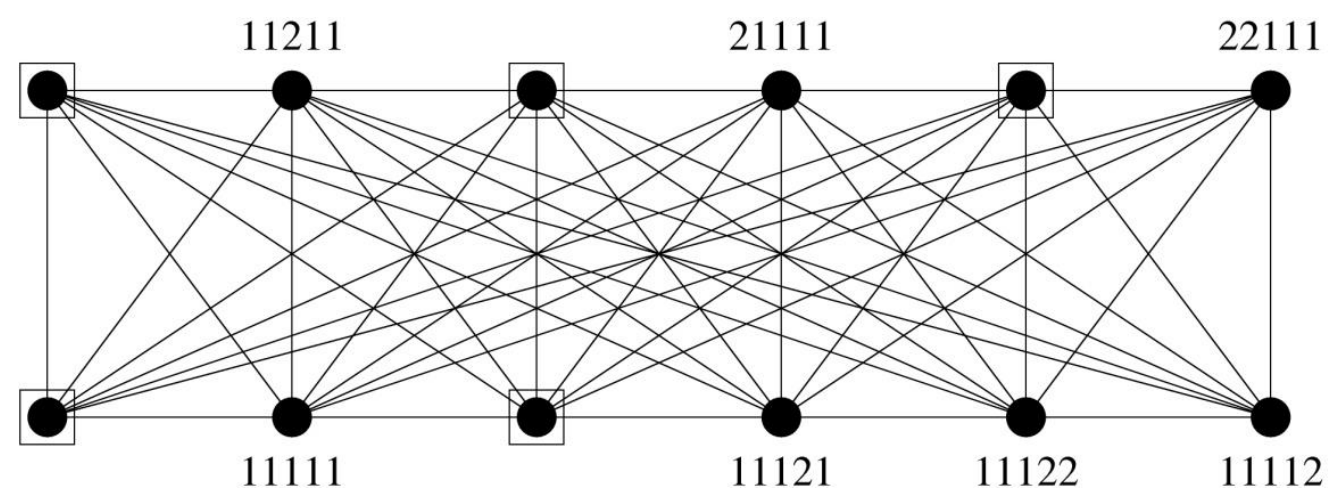

Fig 1. The Metric Dimension of Joint Graph $P_{6}+C_{4}$.

Theorem 2.2. For $n \geq 7$, the metric dimension of amalgamation of parachute $\operatorname{amal}\left(P C_{7}, v, m\right)$ is $\operatorname{dim}\left(\operatorname{amal}\left(P C_{7}, v=A, m\right)\right)=\frac{6 m}{2}$.

Proof. The amalgamation of parasut graph, denoted by $\operatorname{amal}\left(P C_{7}, v, m\right)$ is a connected graph with vertex set $V\left(\operatorname{amal}\left(P C_{7}, v, m\right)\right)=\left\{x_{i}^{j} ; 1 \leq i \leq 7 ; 1 \leq j \leq m\right\} \cup\left\{y_{i}^{j} ; 1 \leq i \leq\right.$ 7; $1 \leq j \leq m\} \cup\{A\}$ and edge set $E\left(\operatorname{amal}\left(P C_{7}, v, m\right)\right)=\left\{A x_{i}^{j} ; 1 \leq i \leq 7 ; 1 \leq j \leq m\right\} \cup$ $\left\{x_{i}^{j} x_{i+1}^{j} ; 1 \leq i \leq 6 ; 1 \leq j \leq m\right\} \cup\left\{y_{i}^{j} y_{i+1}^{j} ; 1 \leq i \leq 6 ; 1 \leq j \leq m\right\} \cup\left\{x_{1}^{j} y_{1}^{j} ; 1 \leq j \leq\right.$ $m\} \cup\left\{x_{7}^{j} y_{7}^{j} ; 1 \leq j \leq m\right\}$. The cardinality of vertex set and edge set, respectively are $\left|V\left(\operatorname{amal}\left(P C_{7}, v, m\right)\right)\right|=14 \mathrm{~m}+1$ and $\left|E\left(\operatorname{amal}\left(P C_{7}, v, m\right)\right)\right|=21 \mathrm{~m}$.

If we show that $\operatorname{dim}\left(\operatorname{amal}\left(P C_{7}, v, m\right)\right) \geq \frac{6 m}{2} \mathrm{r} n=7$, then we will show the best lower bound namely $\operatorname{dim}\left(\operatorname{amal}\left(P C_{7}, v, m\right)\right) \geq \frac{7 m}{2}-1$. Assume that $\operatorname{dim}\left(\operatorname{amal}\left(P C_{7}, v, m\right)\right)<\frac{6 m}{2}$. This can be shown with take resolving set $W=$ $\left\{x_{1}^{1}, x_{4}^{1}, x_{6}^{1}, x_{1}^{2}, x_{4}^{2}, x_{6}^{2}, x_{1}^{3}, x_{4}^{3}, x_{6}^{3}, x_{1}^{4}, x_{4}^{4}, x_{6}^{4}\right\}$ so that it obtained the representation of the vertices $x, y \in V\left(\operatorname{amal}\left(P C_{7}, v, m\right)\right)$ respect to $W$. It can be seen that there is at least two vertices in $\operatorname{amal}\left(P C_{7}, v, 4\right)$ which have the same representation respect to $W$, one of them is $r\left(x_{3}^{1} \mid W\right)=(2,1,2,2,2,2,2,2,2,2,2)$ and $r\left(x_{5}^{1} \mid W\right)=(2,1,2,2,2,2,2,2,2,2,2)$ such that we have the cardinality of resolving set of $\left(\operatorname{amal}\left(P C_{7}, v, m\right)\right) \geq\left\lceil\frac{6 m}{2}\right\rceil$.

Furthermore, we will prove that $\operatorname{dim}\left(\operatorname{amal}\left(P C_{7}, v, m\right)\right) \leq\left\lceil\frac{6 m}{2}\right\rceil$ with determine the resolving set $W=\left\{x_{i}^{j} ; 4 \leq i \leq 7 ; 2 \leq j \leq m ; i=\right.$ odd $\} \cup\left\{x_{1}^{j} ; 1 \leq j \leq m\right\}$. So, we have the cardinality of resolving set of $\operatorname{amal}\left(P C_{7}, v, m\right)$ namely $|W|=\mid\left\{x_{i}^{j} ; 4 \leq i \leq 7 ; 2 \leq\right.$ $j \leq m ; i=o d d\} \cup\left\{x_{1}^{j} ; 1 \leq j \leq m\right\} \mid=\left(\frac{4}{2} m\right)+m=\left(\frac{6 m}{2}\right)$. The representation of the vertices $y \in\left(\operatorname{amal}\left(P C_{7}, v, m=4\right)\right)$ and $x \in\left(\operatorname{amal}\left(P C_{7}, v, m=4\right)\right)$ respect to $W$ as follows.

$$
\begin{aligned}
& r\left(x_{i}^{j} \mid W\right)=\{\left.\left(a_{i k}^{j}\right) ; 1 \leq i \leq n, 1 \leq j \leq m, 1 \leq k \leq \frac{6 m}{2}\right\}, \text { where } \\
& a_{i k}=\left\{\begin{array}{l}
0 ; \text { for } k=1, k=2 i, 2 \leq i \leq\left(\left\lfloor\frac{n}{2}\right\rfloor\right), 1 \leq j \leq m \\
1 ; \text { for } k=\frac{i+1}{2}, 3 \leq i \leq n, i \in \text { odd } \\
1 \leq j \leq m \text { or } k=\frac{i-1}{2}, 5 \leq i \leq 7, i \in \text { odd }, 1 \leq j \leq m \\
2 ; \text { for } 1 \leq j \leq m, k, i=\text { other }
\end{array}\right.
\end{aligned}
$$




$$
\begin{aligned}
& r(y \mid W)=\left.\left(a_{i k}\right) ; 1 \leq i \leq 7,1 \leq k \leq \frac{6 m+2}{2}\right\}, \text { where } \\
& a_{i k}=\left\{\begin{array}{l}
1 ; \text { for } k=3 j-2, i=1,1 \leq j \leq m \\
2 ; \text { for } k=\frac{6 m+2}{2}, i=1,7,1 \leq j \leq m \text { or } k=3 j-2, i=2, \\
1 \leq j \leq m \text { or } k=3 j, i=7,1 \leq j \leq m \\
3 ; \text { for } k=\frac{6 m+2}{2}, i=2,6,1 \leq j \leq m \text { or } k=3 j-2, i=3, \\
1 \leq j \leq m \text { or } k=3 j, i=6,1 \leq j \leq m \text { or } i=1, \\
k \neq 3 j-2 \text { and } k=\frac{6 m+2}{2} \text { or } i=7, k \neq 3 j \text { and } k=\frac{6 m+2}{2} \\
4 ; \text { for } k=\frac{6 m+2}{2}, i=3,5,1 \leq j \leq m \text { or } k=3 j-2, i=4 \\
1 \leq j \leq m \text { or } k=3 j, i=5,1 \leq j \leq m \text { or } i=2, \\
k \neq 3 j-2 \text { and } k=\frac{6 m+2}{2} \text { or } i=6, k \neq 3 j \text { and } k=\frac{6 m+2}{2} \\
5 ; \text { for } k=\frac{6 m+2}{2}, i=3,3 j \text { or } k \neq 3 j-2 \text { and } k \neq \frac{6 m+2}{2}, i=3, \\
\text { or } k \neq 3 j \text { and } k \neq \frac{6 m+2}{2}, i=5 \\
6 ; \text { for } i=4 \text { and } i \neq 3 j \text { and } i \neq 3 j-2 \text { and } i \neq \frac{6 m+2}{2}
\end{array}\right.
\end{aligned}
$$

It can be seen that every vertex in $\operatorname{amal}\left(P C_{7}, v, m\right)$ have distinct representation respect to $W$, such that the cardinality of resolvng set in $\operatorname{amal}\left(P C_{7}, v, m\right)$ is $\frac{6 m}{2}$ or $\operatorname{dim}\left(\operatorname{amal}\left(P C_{7}, v, m\right)\right) \leq \frac{6 m}{2}$. Thus, we conclude that $\operatorname{dim}\left(\operatorname{amal}\left(P C_{7}, v, m\right)\right)=\frac{6 m}{2}$.
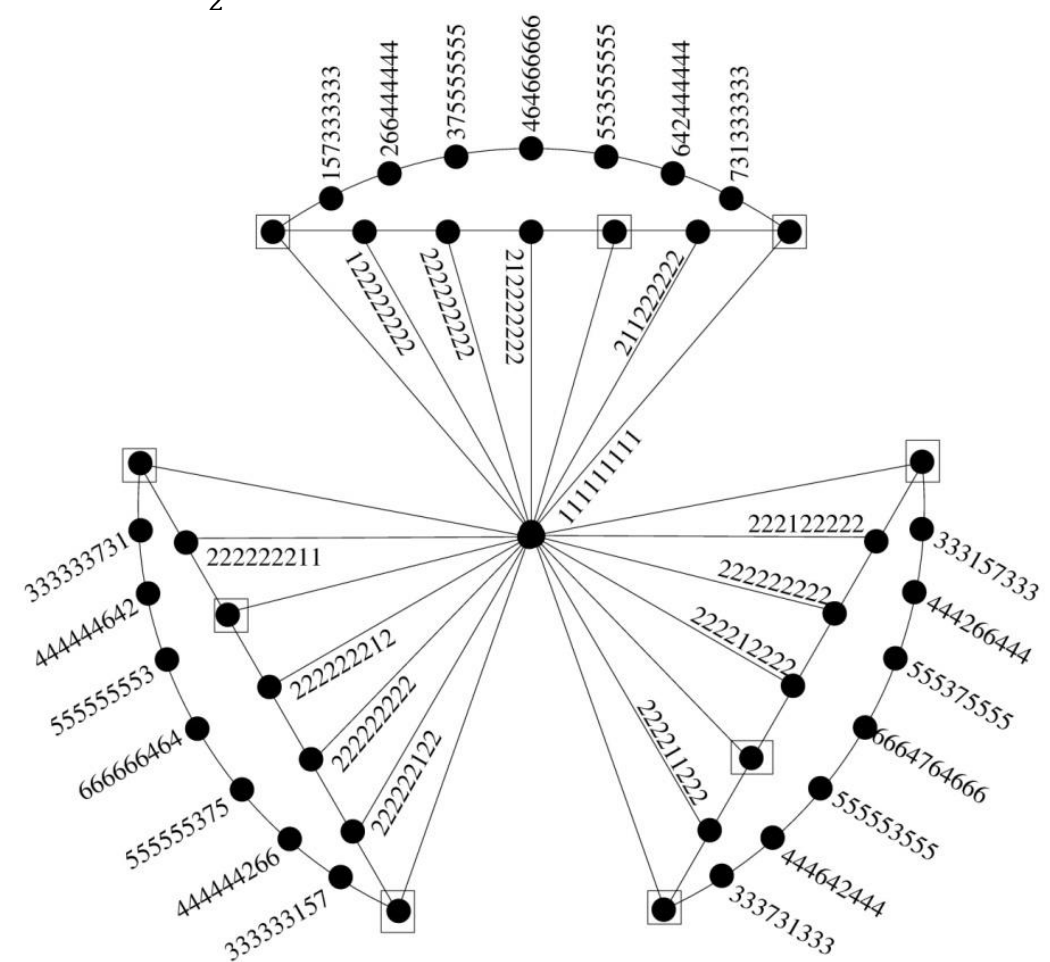

Fig 2. The Metric Dimension of Amalgamation of Parachute Amal $\left(P C_{7}, v, 3\right)$.

Theorem 2.3. For $n \geq 6$, the metric dimension of amalgamation of fan graph $\operatorname{amal}\left(F_{n}, v=y, m\right)$ is: 


$$
\operatorname{dim}\left(\operatorname{aral}\left(F_{n}, v=A, m\right)\right)=\left\{\begin{array}{l}
\frac{n m}{2}-1, \text { for } n \text { is even } \\
\frac{n m-m}{2}, \text { for } n \text { is odd }
\end{array}\right.
$$

Proof. The amalgamation of fan graph, denoted by $\operatorname{amal}\left(F_{n}, v=y, m\right)$ is a connected graph with vertex set $V\left(\operatorname{amal}\left(F_{n}, v=y, m\right)\right)=\left\{x_{i}^{j} ; 1 \leq i \leq n-1 ; 1 \leq j \leq m\right\} \cup$ $\left\{y_{j} ; 1 \leq j \leq m\right\} \cup\left\{x_{n}^{m}\right\}$ and edge set $E\left(\operatorname{amal}\left(F_{n}, v=y, m\right)\right)=\left\{x_{i}^{j} x_{i+1}^{j} ; 1 \leq i \leq n-\right.$ $2 ; 1 \leq j \leq m\} \cup\left\{y_{j} x_{i}^{j} ; 1 \leq i \leq n-1 ; 1 \leq j \leq m\right\} \cup\left\{x_{n-1}^{j} x_{1}^{j+1} ; 1 \leq j \leq m-1\right\} \cup$ $\left\{x_{n-1}^{m} x_{n}^{m}\right\} \cup\left\{y_{j} x_{1}^{j+1} ; 1 \leq j \leq m-1\right\} \cup\left\{y_{m} x_{n}^{m}\right\}$. The cardinality of vertex set and edge set, respectively are $\left|V\left(\operatorname{amal}\left(F_{n}, v=y, m\right)\right)\right|=n m+1$ and $\left|E\left(\operatorname{amal}\left(F_{n}, v=y, m\right)\right)\right|=$ $m(2 n-1)$.

If we show that $\operatorname{dim}\left(\operatorname{amal}\left(F_{n}, v=y, m\right)\right)=\frac{n m}{2}-1$ for $n \geq 7$ and $n$ is even, then we will show the best lower bound namely $\operatorname{dim}\left(\operatorname{amal}\left(F_{n}, v=y, m\right)\right) \geq \frac{n m}{2}-1$. Assume that $\operatorname{dim}\left(\operatorname{amal}\left(F_{n}, v=y, m\right)\right)<\frac{n m}{2}-1$. This can be shown with take resolving set $W=$ $\left\{x_{1}^{1}, x_{4}^{1}, x_{1}^{2}, x_{4}^{2}, x_{6}^{2}, x_{1}^{3}, x_{4}^{3}, x_{6}^{3}, x_{1}^{4}, x_{4}^{4}\right\}$ so that it obtained the representation of the vertices $y \in V\left(\operatorname{aral}\left(F_{6}, v=y, 4\right)\right)$ and $x_{i}^{j} \in V\left(\operatorname{amal}\left(F_{n}, v=6,4\right)\right)$ respect to $W$. It can be seen that there is at least two vertices in $\operatorname{amal}\left(F_{6}, v=y, 4\right)$ which have the same representation respect to $W$, one of them is $r\left(x_{6}^{1} \mid W\right)=(2,2,2,2,2,2,2,2,2,2)$ and $r\left(x_{6}^{4} \mid W\right)=(2,2,2,2,2,2,2,2,2,2)$ such that we have the cardinality of resolving set of $\operatorname{dim}\left(\operatorname{aral}\left(F_{n}, v=y, m\right)\right) \geq \frac{n m}{2}-1$.

Furthermore, we will prove that $\operatorname{dim}\left(\operatorname{amal}\left(F_{n}, v=y, m\right)\right) \leq \frac{n m}{2}-1$ with determine the resolving set $W=\left\{x_{i}^{j} ; 4 \leq i \leq n ; 2 \leq j \leq m ; i=\right.$ odd $\}-\left\{x_{n}^{m}\right\} \cup\left\{x_{1}^{j} ; 1 \leq\right.$ $j \leq m\}$. So, we have the cardinality of resolving set of $\operatorname{amal}\left(F_{n}, v=y, m\right)$ namely $|W|=$ $\mid\left\{x_{i}^{j} ; 4 \leq i \leq n ; 1 \leq j \leq m ; i\right.$ is even $\}-\left\{x_{n}^{m}\right\} \cup\left\{x_{1}^{j} ; 1 \leq j \leq m\right\} \mid=\left(\frac{n-2}{2}\right) m+m-1=$ $\left(\frac{n m}{2}-1\right)$. The representation of the vertices $y \in F_{n}$ and $x \in F_{n}$ respect to $W^{\prime}$ as follows.

$$
\begin{gathered}
r\left(x_{i}^{j} \mid W\right)=\left\{\left(a_{i k}^{j}\right) ; 1 \leq i \leq n, 1 \leq j \leq m, 1 \leq k \leq \frac{n m}{2}-1\right\}, \text { where } \\
a_{i k}=\left\{\begin{array}{l}
\left.0 ; \text { for } k=1, k=2 i, 2 \leq i \leq\left(\mid \frac{n}{2}\right]\right), 1 \leq j \leq m \\
1 ; \text { for } k=\frac{i+1}{2}, 3 \leq i \leq n, i \in \text { odd }, 1 \leq j \leq m \\
k=\frac{i-1}{2}, 5 \leq i \leq n, i \in \text { odd }, 1 \leq j \leq m \text { and }(k \neq m \cap i \neq n) \\
2 ; \text { for } 1 \leq j \leq m, k, i=\text { others }
\end{array}\right. \\
r(y \mid W)=\left\{\begin{array}{l}
\left.\left(a_{i k}\right) ; 1 \leq i \leq n, 1 \leq k \leq \frac{n-2}{2}\right\}, \text { where } \\
a_{i k}=\left\{1 ; \text { for } 1 \leq k \leq \frac{n m-n}{2}, i=1\right.
\end{array}\right.
\end{gathered}
$$

It can be seen that every vertex in $\operatorname{amal}\left(F_{6}, v, 4\right)$ have distinct representation respect to $W$, such that the cardinality of resolvng set in $\operatorname{amal}\left(F_{n}, v, m\right)$ is $\frac{\mathrm{nm}}{2}-1$ or $\operatorname{dim}\left(\operatorname{amal}\left(F_{n}, v, m\right)\right) \leq \frac{n m}{2}-1$. Thus, we conclude that $\operatorname{dim}\left(\operatorname{amal}\left(F_{n}, v, m\right)\right)=\frac{n m}{2}-1$. 


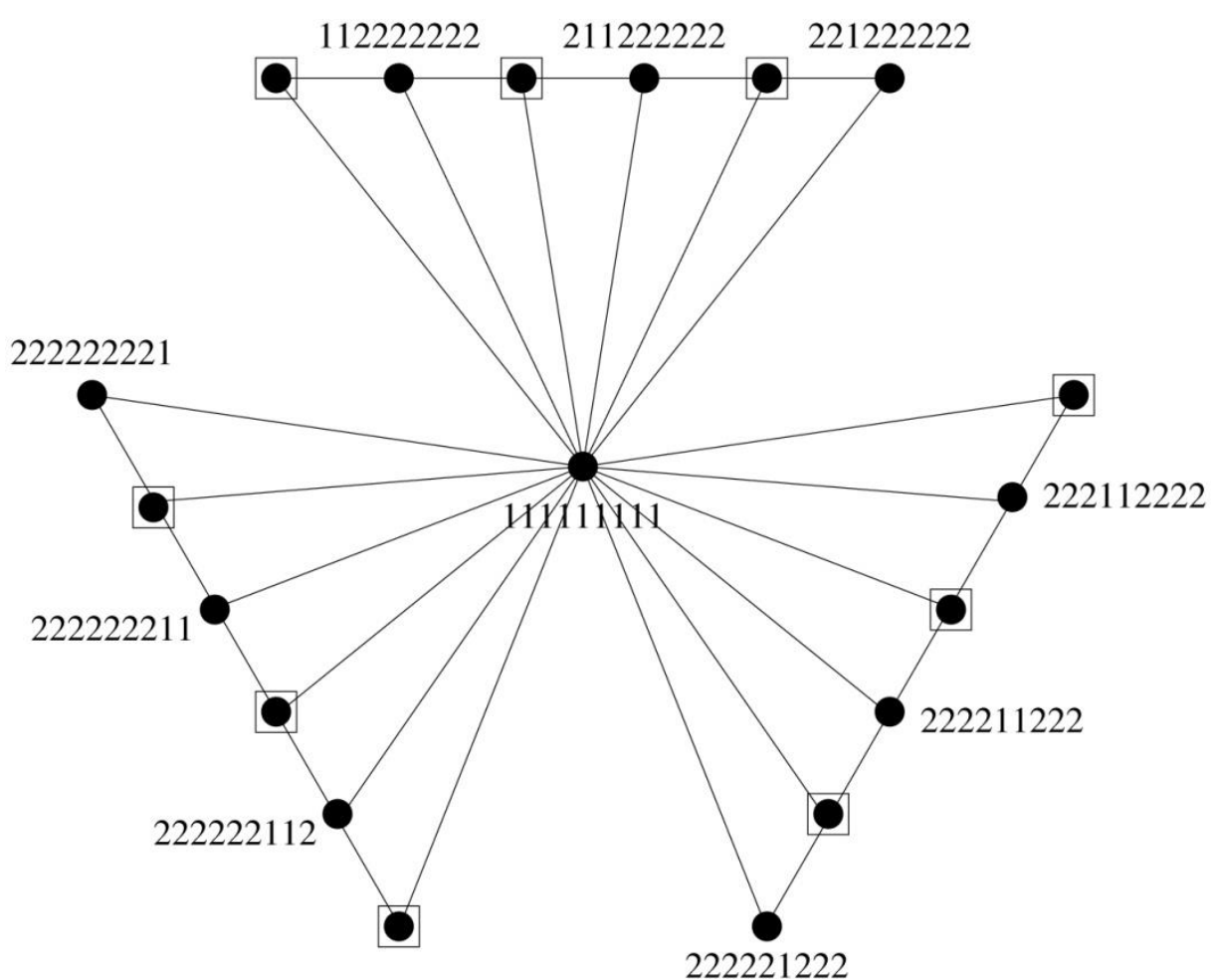

Fig 3. The Metric Dimension of Amalgamation of Fan Graph $\operatorname{Amal}\left(F_{6}, v=y, 3\right)$.

Theorem 2.4. For $m \geq 2$, the metric dimension of $\operatorname{shack}\left(H_{2}^{2}, e, m\right)$ is $\operatorname{dim}\left(\operatorname{shack}\left(H_{2}^{2}, e, m\right)\right)=2$.

Proof. The shackle of fan graph, denoted by $\operatorname{shack}\left(H_{2}^{2}, e, m\right)$ is a connected graph with vertex set $V\left(\operatorname{shack}\left(H_{2}^{2}, e, m\right)\right)=\left\{x_{j} ; 1 \leq j \leq m+1\right\} \cup\left\{y_{j} ; 1 \leq j \leq m+1\right\}$ and edge set $E\left(\operatorname{shack}\left(H_{2}^{2}, e, m\right)\right)=\left\{x_{j} y_{j} ; 1 \leq j \leq m+1\right\} \cup\left\{x_{j} y_{j+1} ; 1 \leq j \leq n\right\} \cup\left\{x_{j+1} y_{j} ; 1 \leq j \leq\right.$ $m\}$. The cardinality of vertex set and edge set, respectively are $\left|V\left(\operatorname{shack}\left(H_{2}^{2}, e, m\right)\right)\right|=$ $2 m+2$ and $\left|E\left(\operatorname{shack}\left(H_{2}^{2}, e, m\right)\right)\right|=3 m+1$.

The proof that the lower bound of $\operatorname{shack}\left(H_{2}^{2}, e, m\right)$ is $\operatorname{dim}\left(\operatorname{shack}\left(H_{2}^{2}, e, m\right)\right) \geq 2$. Based on Proposition 1 , that $\operatorname{dim}(G)=1$ if only if $G \cong P_{n}$. The graph $\operatorname{shack}\left(H_{2}^{2}, e, m\right)$ does not isomorphic to path $P_{n}$ such that $\operatorname{dim}\left(\operatorname{shack}\left(H_{2}^{2}, e, m\right)\right) \geq 2$. Furthermore, we proof that the upper bound of $\operatorname{shack}\left(H_{2}^{2}, e, m\right)$ is $\operatorname{dim}\left(\operatorname{shack}\left(H_{2}^{2}, e, m\right)\right) \leq 2$, we choose the resolving set $W=\left\{x_{1}, y_{1}\right\}$.

The representation of the vertices $v \in V\left(\operatorname{shack}\left(H_{2}^{2}, e, m\right)\right)$ respect to $W$ as follows.

$$
\begin{array}{ll}
r\left(x_{j} \mid W\right)=(j-1, j) ; j \in \text { odd } & r\left(y_{j} \mid W\right)=(j, j-1) ; j \in \text { odd } \\
r\left(x_{j} \mid W\right)=(j, j-1) ; j \in \text { even } & r\left(y_{j} \mid W\right)=(j-1, j) ; j \in \text { even }
\end{array}
$$

Vertex $v \in V\left(\operatorname{shack}\left(H_{2}^{2}, e, m\right)\right)$ are distict. So, we have the cardinality of resolving set $W$ is $|W|=2$. Thus, the upper bound of $\operatorname{shack}\left(H_{2}^{2}, e, m\right)$ is $\operatorname{dim}\left(\operatorname{shack}\left(H_{2}^{2}, e, m\right)\right) \leq 2$. It concludes that $\operatorname{dim}\left(\operatorname{shack}\left(H_{2}^{2}, e, m\right)\right)=2$. 


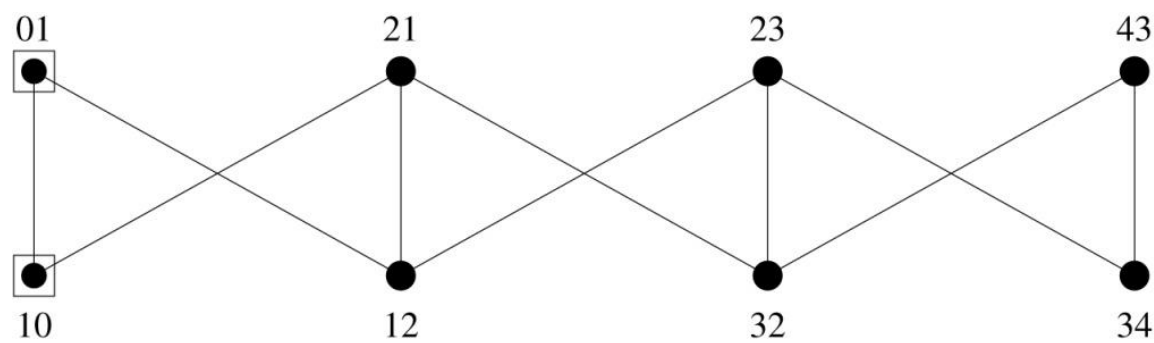

Fig 4. The Metric Dimension of Shack $\left(H_{2}^{2}, e, 3\right)$.

\section{CONCLUSIONS}

In this paper, the result show that the local metric dimension of some graph operation such as joint graph $P_{n}+C_{m}$, amalgamation of parachute, amalgamation of fan, and $\operatorname{shack}\left(H_{2}^{2}, e, m\right)$.

\section{ACKNOWLEDGMENTS}

We gratefully acknowledge the support from DRPM KEMENRISTEKDIKTI 2018 indonesia.

\section{REFERENCES}

[1] G. Chartrand, E. Salehi, and P. Zhang, "The partition dimension of a graph," Aequationes Math., vol. 59, pp. 45-54, 2000.

[2] G. Chartrand, L. Eroh, and M. A. Johnson, " Resolvability in graphs and the metric dimension of a graph," Discrate Appl. Math., vol. 105, pp. 99-113, 2000.

[3] Marsidi, Dafik, I. H. Agustin, and R. Alfarisi, "On the local metric dimension of line graph of special graph," CAUCHY, vol. 4, no. 3, pp. 125-130, 2016.

[4] I. G. Yero, D. Kuziak, and J. S. Rodríguez-Velázquez, "On the metric dimension of corona product graphs," Computers and Mathematics with Applications, vol. 61, pp. 2793-2798, 2011.

[5] H. Fernau, P. Heggernes, P. Hof, D. Meister, and R. Saei, "Computing the metric dimension for chain graphs," Information Processing Letters, vol. 115, pp. 671-676, 2015.

[6] J. Cáceres, C. Hernando, M. Mora, I. M. Pelayo, and M. L. Puertas, "On the metric dimension of infinite graphs," Discrete Applied Mathematics, vol. 160, pp. 2618-2626, 2012.

[7] M. Fehr, S. Gosselin, and O. R. Oellermann, "The metric dimension of cayley digraphs," Discrete Mathematics, vol. 360, pp. 31-41, 2006.

[8] T. K. Maryati, A. N. M. Salman, and E. T. Baskoro, "On H-supermagic labelings for certain shackles and amalgamations of a connected graph," Utilitas Mathematica, 2010.

[9] I. H. Agustin, Dafik, S. Latifah, and R. M. Prihandini, "A super (A,D)-Bm-antimagic total covering of a generalized amalgamation of fan graphs," CAUCHY, vol. 4, no. 4, pp. 146154, 2017. 